\title{
Brain Amyloidoma: Case Report and Literature Review
}

\author{
Abd El Kader Moumouni ${ }^{1,2 *}$, Daniel Memia Zolo', Essossinam Kpelao ${ }^{3}$, Pascal Compaore ${ }^{1}$, \\ Dabou Abiba Tamou Tabe ${ }^{4}$, Latevi Lawson ${ }^{3}$, Pwerew Rodolphe Plante ${ }^{2}$, \\ Edem Kossi Gueouguede ${ }^{2}$, Benedicte Souho², Abderrahmane Hamlat ${ }^{1}$
}

\author{
${ }^{1}$ Department of Neurosurgery, CHU Martinique, Martinique, France \\ ${ }^{2}$ Department of Neurosurgery, CHU Kara, Kara, Togo \\ ${ }^{3}$ Department of Neurosurgery, CHU Sylvanus Olympio, Lomé, Togo \\ ${ }^{4}$ Departments of Radiology, CHR Kara, Kara, Togo \\ Email: *makmas2003@gmail.com
}

How to cite this paper: El Kader Moumouni, A., Memia Zolo, D., Kpelao, E., Compaore, P., Tamou Tabe, D.A., Lawson, L., Plante, P.R., Gueouguede, E.K., Souho, B. and Hamlat, A. (2020) Brain Amyloidoma: Case Report and Literature Review. Open Journal of Modern Neurosurgery, 10, 403-421.

https://doi.org/10.4236/ojmn.2020.104043

Received: May 25, 2020

Accepted: August 21, 2020

Published: August 24, 2020

Copyright ( 2020 by author(s) and Scientific Research Publishing Inc. This work is licensed under the Creative Commons Attribution International License (CC BY 4.0).

http://creativecommons.org/licenses/by/4.0/ (c) (i) Open Access

\begin{abstract}
Introduction: Primary deposition of amyloid can take several forms including amyloidoma organ restricted among which is brain. Brain amyloidoma can mimic several lesions and offers a diagnostic challenge to the physician. The present work reports an additional case and summarizes the salient characteristics of previously published cases. Case Report: A 61-year-old, woman experienced paroxystic auditory hallucinations followed at times by generalized tonico-clonic seizures. Examination revealed a mild left pyramidal weakness. Head CT scan and MRI revealed a lobular lesion of the right atrium with contrast enhancement. The diagnosis of amyloidoma Lambda light chain $(\lambda \mathrm{LC})$ type was performed by means of a stereotactic biopsy. The patient was treated by 3 cures of high dose methotrexate $\left(15 \mathrm{mg} / \mathrm{m}^{2}\right)$. At 24 months follow up the patient remains stable clinically and biologically. The 2 years follow-up MRI showed the same findings. Conclusion: No guidelines can be suggested for brain amyloidoma treatment; the "wait and see" was the mind-set in the literature. However, a non-tumour like pattern of a cerebral mass developing near the ventricle with a fine, irregular radiating margin enhancement and lack of oedema, and mass effect are important MRI clues for brain amyloidoma diagnosis. The diagnosis is histological after biopsy or excision.
\end{abstract}

\section{Keywords}

Amyloidoma, Brain, Literature Review

\section{Introduction}

Cerebral amyloidoses are part of a complex group of chronic and progressive 
diseases caused by protein folding and metabolism abnormalities, bracketed under the denomination of "protein folding disorders" [1]. Their origin is unknown, and characterized by the deposition, in different brain sites, of an insoluble fibrillary proteinaceous substance, generically called amyloid.

Primary deposition of amyloid in the brain can take several forms including senile plaques (Alzheimer disease), Spongiform encephalopathy's, diffuse vascular deposit in meningo-cortical vessels (cerebral amyloid angiopathy-CAA), and focal mass like deposition (amyloidoma) [2].

Amyloidoma organ restricted is defined as primary solitary amyloidosis where no plasma-cell dyscrasia or abnormal serum proteins are detectable [3] [4]. The first report of brain amyloidoma was published by Saltykow [4] [5]. Since amyloidomas have been reported in several nervous system (CNS) locations [3] [6][15].

Amyloidoma can mimic several brain lesions [16] [17] [18] [19] and offers a diagnostic challenge to the physician. Even the histology has been given diagnosis after surgery the lesion remains problematic in terms of treatment and prognosis [20] [21].

The present work reports an additional case and summarizes the salient features of the previously published cases.

\section{Patient and Method}

\subsection{Case Report}

A 61-year-old, right-handed, Caucasian woman was admitted at local hospital on July 2010 with a recent history of paroxystic auditory hallucinations (music and bell sounds) at times followed by generalized tonico-clonic seizures. Initial cranial Computed Tomography (CT) scan [Figure 1(A)] revealed a lobular hyper-density in the right atrium with contrast enhancement [Figure 1(B)].

On admission, examination revealed a mild left pyramidal weakness with symmetrical and normal myotatic reflexes. The mental status, speech, cranial nerves, gait, and sensory examination were normal. There were no clinical signs of increased intracranial pressure and the remaining physical examination was unremarkable as were patient's and family's history.

Laboratory assay including full blood count, erythrocyte sedimentation rate, serologic test for HIV, hepatic and renal functional tests were normal as were the electrocardiogram and the chest $\mathrm{x}$-ray.

Magnetic resonance imaging (MRI); Fluid-Attenuated Inversion Recovery (Flair) sequences showed a right parietal infiltrating lesion [Figure 2(A)]. On T1-weighted image (WI) it showed a slight heterogeneous hypo signal [Figure 2(B)]. On T2-WI the lesion showed a patchy hypo-hyper signals [Figure 2(C)]. Following contrast infusion the lesion disclosed heterogeneous enhancement [Figures 2(D)-(F)]. On diffusion sequences the apparent diffusion coefficient (ADC) was high, while perfusion sequences revealed delayed perfusion without hyper perfusion within the enhanced area. The spectroscopy study disclosed a 


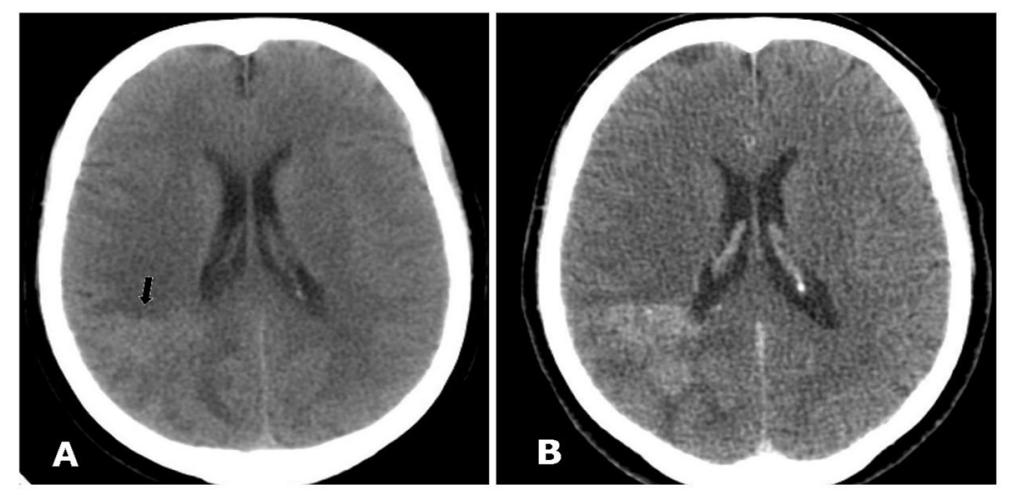

Figure 1. Initial cranial Computed Tomography (CT) scan (A) revealed a lobular hyper-density in the right atrium with contrast enhancement (B).
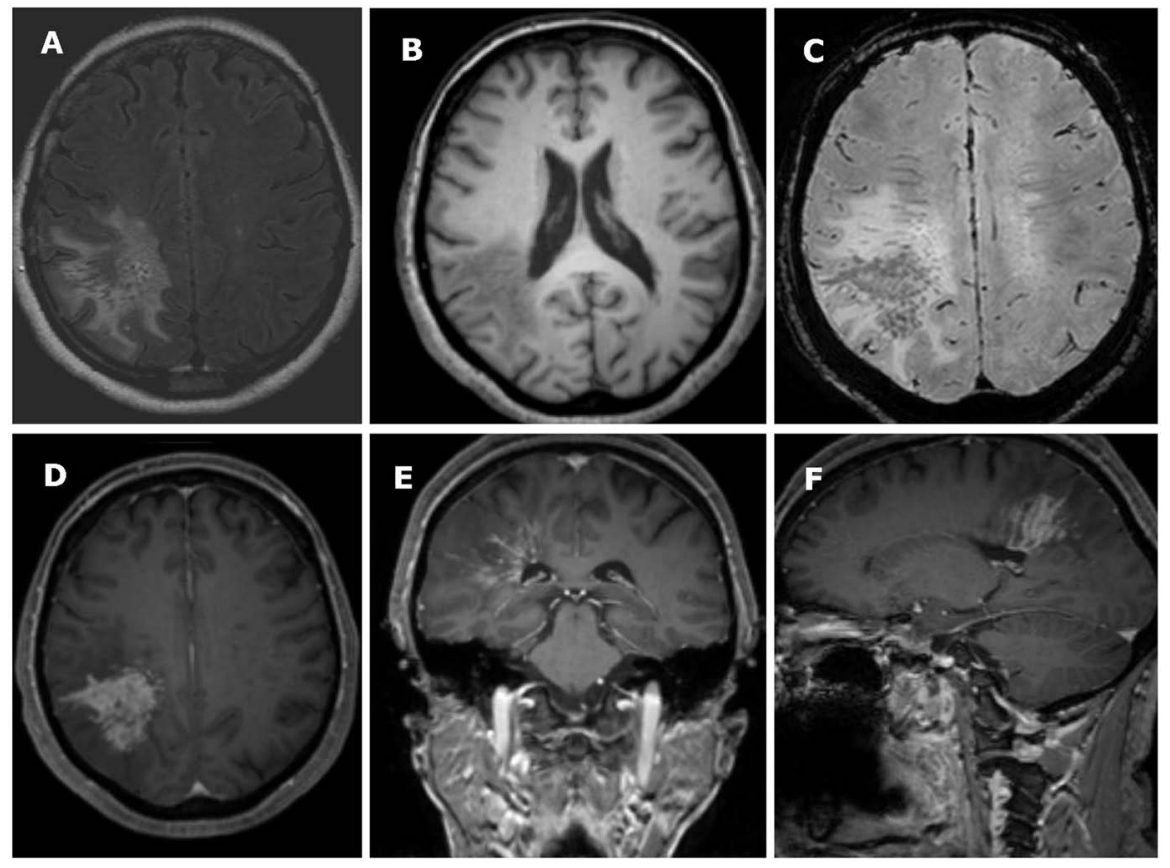

Figure 2. Magnetic resonance imaging (MRI); Fluid-Attenuated Inversion Recovery (Flair) sequences showed a right parietal infiltrating lesion (A). On T1-weighted image (WI) it showed a slight heterogeneous hypo signal (B). On T2-WI the lesion showed a patchy hypo-hyper signals (C). Following contrast infusion the lesion disclosed heterogeneous enhancement (D)-(F). On diffusion sequences the apparent diffusion coefficient (ADC) was high, while perfusion sequences revealed delayed perfusion without hyper perfusion within the enhanced area.

lipid pick. [Figure 3(A), Figure 3(B)].

The suggested diagnosis was brain lymphoma. Several specimens were retrieved, by means of stereotactic biopsy, from more than one site of the tumour. The post-operative course was uneventful.

Pathological findings: Several brain specimen measuring between 0.2 to 0.5 $\mathrm{cm}$ were embedded in paraffin and stained with haematoxylin and eosin (HE), periodic acid-Schiff (PAS), Prussian blue reagent (or Perl's reagent), May-Grünwald Giemsa (MGG), and Congo red stains. 


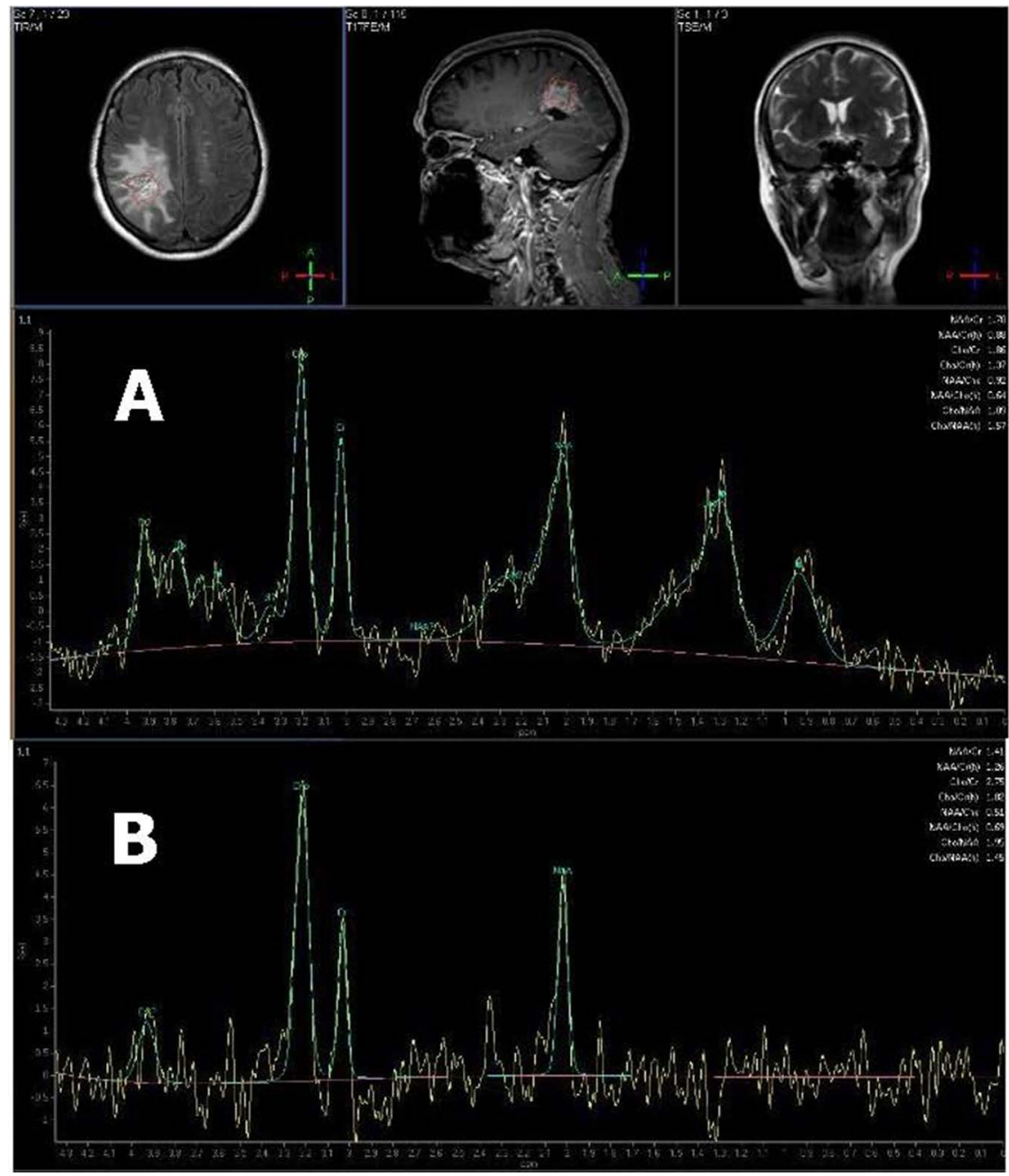

Figure 3. The spectroscopy study.

Microscopy: On HE-stained sections [Figure 4(A)], the tissue specimens were composed of abnormal spongiotic brain white matter containing disseminated well limited monomorphous, acellular, pale, eosinophilic deposits with a slight peri vascular lymphocytic infiltrate. No microscopic infarctions or evidence of old haemorrhagic foci such as perivascular hemosiderin-laden macrophages were found and the specimens showed no increase in cellularity or neoplastic infiltrates. The eosinophilic deposit stained brick colour in Congo red preparation [Figure 4(B)] and pink in PAS preparation. The deposit exhibited the dichromism and apple green birefringence under polarized light characteristic of amyloid [Figure 4(C)].

Immunohistochemistry: Staining with Lambda $(\lambda)$ amyloid antibody showed a strong labelling of the deposit [Figure 4(D)]. Additional tissue sections stained immunohisto-chemically with monoclonal antibodies against Beta and Kappa $(\kappa)$ amyloid, Prion, TAU, glial fibrillary acidic protein, Synaptophysine, and Ki67, were negative. Staining with anti CD138 showed some plasmocytic elements, whereas anti CD34 disclosed a slight increase of the vasculature network. 

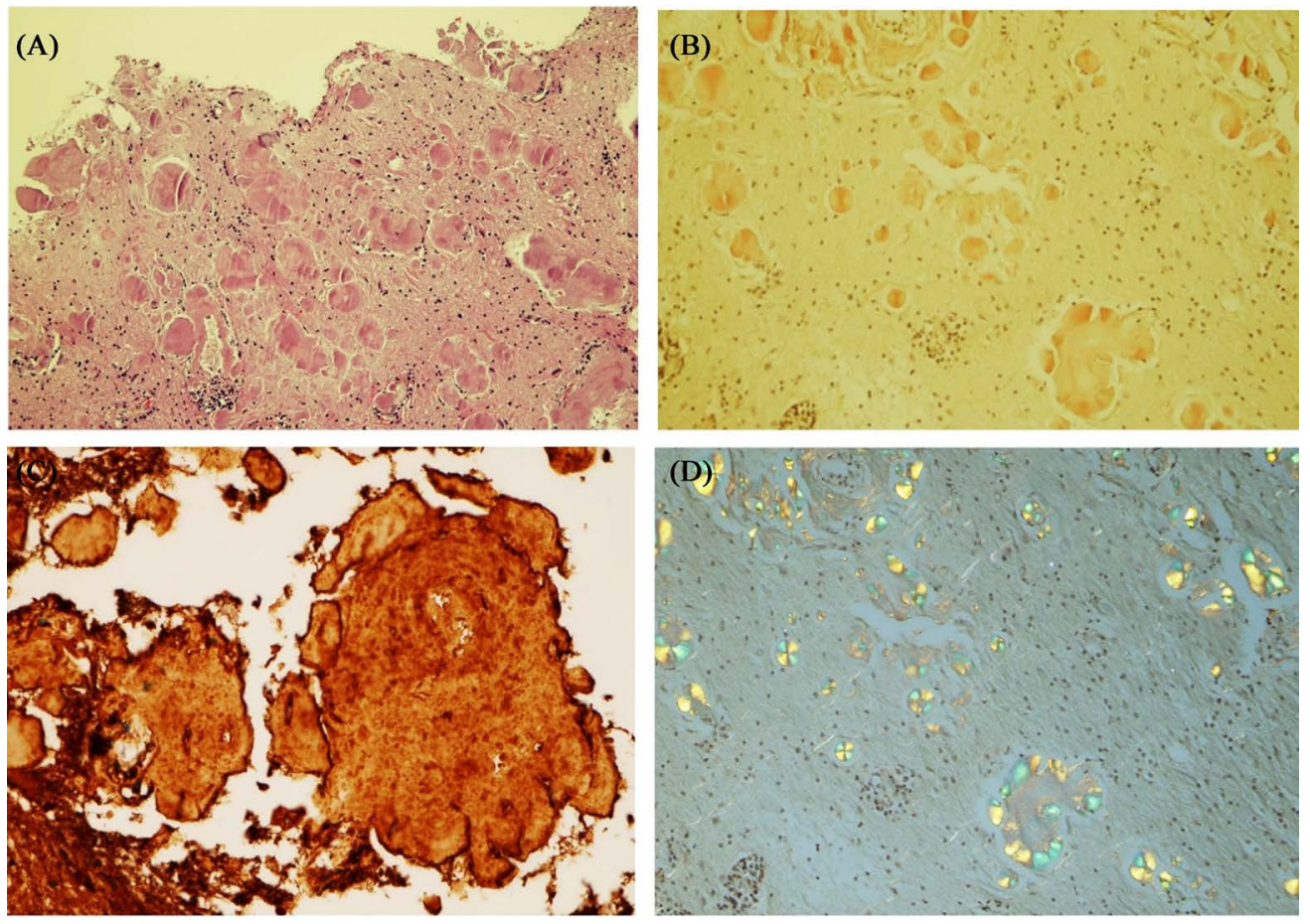

Figure 4. Microscopy: On HE-stained sections (A), the tissue specimens were composed of abnormal spongiotic brain white matter containing disseminated well limited monomorphous, acellular, pale, eosinophilic deposits with a slight peri vascular lymphocytic infiltrate. The eosinophilic deposit stained brick colour in Congo red preparation (B) and pink in PAS preparation. The deposit exhibited the dichromism and apple green birefringence under polarized light characteristic of amyloid (C). Immunohistochemistry: Staining with Lambda $(\lambda)$ amyloid antibody showed a strong labelling of the deposit (D).

The final pathologic diagnosis was cerebral amyloidoma Lambda light chain $(\lambda \mathrm{LC})$ type. The patient was initially treated with corticotherapy and Phenobarbital and referred to Internal Medicine Department, with an unchanged clinical examination.

On extensive staging evaluation, no evidence of clinical symptom or syndrome suggestive of systemic amyloidoses was found. Additional laboratory assay including C-reactive protein level, liver, and renal function tests were normal. Serum protein electrophoresis revealed a slight increase in the monoclonal Ig M Lambda $(1.37 \mathrm{~g} / \mathrm{dl})$ whereas urinary electrophoresis was normal. CT scan of the chest, abdomen and pelvis were normal, as were trans-thoracic echocardiography with Doppler studies, and salivary gland biopsy. Bone marrow biopsy showed a normal maturation of the hematopoietic system cells and both the degree of plasmacytosis and the morphology of plasma cells were normal and no cell suggestive of malignancy was found. In the present case, no finding could support the diagnosis of systemic amyloidosis or multiple myeloma. The French Amyloidosis Centre confirmed the diagnosis of brain amyloidoma with MGUS. The patient was treated by 3 cures of high dose methotrexate $\left(15 \mathrm{mg} / \mathrm{m}^{2}\right)$. At 24 months follow up the patient remains stable clinically and biologically. The 2-years follow-up MRI showed the same findings [Figures 5(A)-(C)]. 


\subsection{Litterature Review}

\section{Materials and Methods}

To identify relevant articles, MEDLINE and GOOGLE SCHOLAR search was performed using the following combinations of keywords: "amyloidoma" and "brain" or "intracranial" or "central nervous system". No language restrictions were applied and no time limit. Articles were eligible for inclusion if they dealt with brain amyloidoma. Furthermore, references cited in the selected articles were reviewed for additional relevant reports. Data were independently extracted by three authors (AH, YD, and SD) and differences were resolved by consensus.

\section{1) Inclusion criteria}

Thirty-nine reports describing 47 patients harbouring brain amyloidoma with enough clinical, radiological and biological data were selected (Table 1). Although amyloidomas of plexuses choroids were excluded, 2 cases invading the brain parenchyma described by Lampert [6] and Laeng [7] were included.
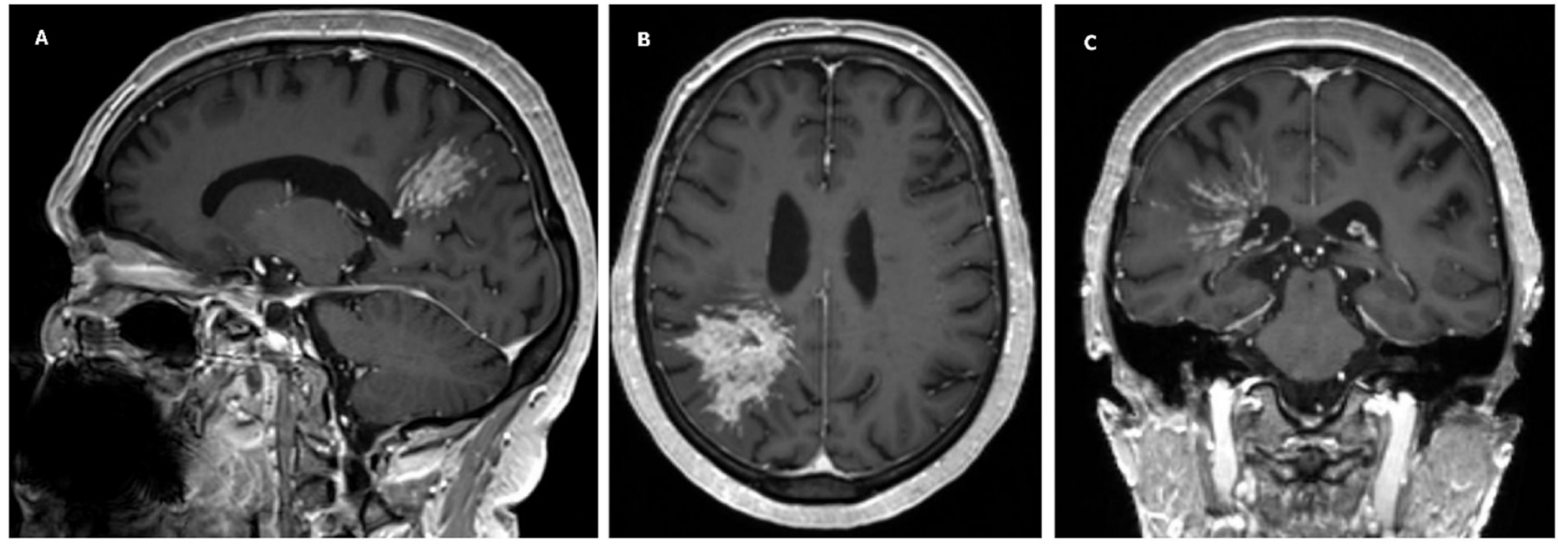

Figure 5. The 2-years follow-up MRI showed the same findings.

Table 1. Clinical characteristics of the published cases.

\begin{tabular}{|c|c|c|c|c|c|c|}
\hline & $\begin{array}{l}\text { Number and } \\
\text { sex of cases }\end{array}$ & $\begin{array}{l}\text { Mean of } \\
\text { Duration }\end{array}$ & $\begin{array}{l}\text { Mean of } \\
\text { Age }\end{array}$ & Surgery & $\begin{array}{l}\text { Mean of } \\
\text { Follow up }\end{array}$ & reference \\
\hline Seizure & $14(8 \mathrm{~F}, 6 \mathrm{M})$ & $3.9 \mathrm{y}$ & 45.8 & $\begin{array}{l}\text { Stereotaxic biopsy (7), open biopsy (1), } \\
\text { excision (4), autopsy (1), NA(1) }\end{array}$ & $4.6 y, \mathrm{NA}(9)$ & [7] [16] [27] [29]-[35] [53] [54] \\
\hline Neuro Def & $21(13 \mathrm{~F}, 8 \mathrm{M})$ & $5.7 y$ & 52.7 & $\begin{array}{l}\text { Stereotaxic biopsy (10), open biopsy ( } 7 \text { ), } \\
\text { excision (3), autopsy (1) }\end{array}$ & $3.4 y, N A(13)$ & $\begin{array}{l}{[4][7][8][17][19][20][25]} \\
{[26][36][38][39][40][41][45]} \\
{[46][47][49][52]}\end{array}$ \\
\hline Co Def & $7(6 \mathrm{~F}, 1 \mathrm{M})$ & $1.9 \mathrm{y}$ & 60.3 & Stereotaxic biopsy (3), autopsy (4) & $1.3 \mathrm{y}, \mathrm{NA}(4)$ & [5] [6] [7] [18] [25] [50] \\
\hline Seizure + CoD & $2(1 \mathrm{~F}, 1 \mathrm{M})$ & $4 y$ & 56 & open biopsy (1), Stereotaxic biopsy (1) & $5 y, N A(1)$ & [37] [44] \\
\hline Co+ Neuro Def & $1(\mathrm{M})$ & 0.5 & 59 & Stereotaxic biopsy & $\mathrm{NA}(1)$ & {$[51]$} \\
\hline Loss of Cons & $1(\mathrm{M})$ & NA & 64 & Open biopsy & NA(1) & {$[43]$} \\
\hline Autopsy & $1(\mathrm{M})$ & NA & 60 & Autopsy & $\mathrm{NA}(1)$ & [42] \\
\hline NA & $1(\mathrm{M})$ & NA & 35 & Excision & $\mathrm{NA}(1)$ & [48] \\
\hline
\end{tabular}

$\mathrm{Y}=$ year, $\mathrm{F}$ = female; $\mathrm{M}$ = male; Neuro Def = neurological deficit, $\mathrm{Co}$ def = cognitive deficit; Loss consc = loss of consciousness; $\mathrm{NA}=$ not available. 


\section{2) Exclusion criteria}

The cases of Tomiyasu et al. [22], Parmar et al. [23], and Jährig et al. [24] were excluded because previously reported respectively by Townsend et al. [25], Ghandi et al. [16], and Spaar et al. [26]. Two unpublished cases have been cited by Harris [27] and Hawkins [28]. We excluded amyloidoma of cranial bones, plexus choroid, nerves and spine as well as the pseudo tumoral forms of cerebral amyloid angiopathy (tCAA). Light chain deposit disease (LCDD) and others non amyloid deposit of the brain were also ruled out.

\section{Results}

There were 48 patients (including the present one): 28 women and 20 men. The overall mean age at presentation was 52 years (range: $15-76$ ). The mean age for men was 50 years (range: $15-76$ ) and that of women 53 years (range: $26-73$ ) (Table 1).

The mean duration of symptoms before diagnosis was 54 months (range 1 444 months).

Protean progressive neurological signs revealed the disease in 22 cases although the most common presenting symptom is seizure (16 cases). Cognitive function deterioration was an inaugural feature in 10 cases. Like in our case, most cases seizure was linked to a normal neurological examination [16] [27] [29]-[34] and it was the onset in 10 out of 27 patients with a solitary lesion [7] [16] [27] [29] [30] [31] [34] [35] while neurological and cognitive deteriorations were the onset in 16 out of 20 patients experiencing multiple lesions [5] [6] [7] [8] [18] [19] [25] [26] [36]-[41].

CT scan and MRI data were, respectively, more or less available in 24 and 31 reports (Table 2). Amyloidoma was a solitary lesion in 28 instances [4] [7] [8] [16] [17] [20] [25] [27] [29] [30] [31] [34] [35] [42]-[52] and multiple in 20 cases. This pathology is most of the time found in the cerebellum with an equal distribution between left (16 cases) and right (17 cases) hemisphere, while both hemispheres involvement occurred in 15 instances [5] [6] [7] [8] [18] [25] [26] [36] [37] [38] [40] [41] [53] including a case of bilateral amyloidoma of plexuses choroid [7]. Nearly all lesions develop within the supra tentorial compartment but in 4 patients the lesions are both supra and infra tentorial with the pons constantly involved [6] [19] [41] [53]. The most frequent site is the para ventricular area, although 5 involved the cortical or sub-cortical region without para ventricular connexion [20] [26] [30] [42].

On native CT scan, although amyloidoma shows more frequently a homogeneous or heterogeneous hyper-density, it may have an iso, or hypo-dense aspect. Following iodine infusion it enhances constantly revealing various aspects including nodular [7] [8] [30], irregularly delineated [17] [30], comet shaped [16], patchy [27], and ring like enhancement [49]. Calcification [19] [20] [27] [31] [54], oedema [7] [8] [16] [30] [52] and mass effect (see Table 2) are scarce.

On MRI, the lesion discloses a hyper, iso, or hypo-intense signal on T1-WI 
Table 2. Radiological and immunhistochemical characteristics of the published cases.

\begin{tabular}{|c|c|c|c|}
\hline & & Features (Number) & Reference \\
\hline \multirow[t]{2}{*}{$\mathrm{CT}$} & CT- & $\begin{array}{l}\text { Hyper (18), hypo ( } 3 \text { ), iso (1), mixte (1), } \\
\text { NA ( } 25)\end{array}$ & $\begin{array}{l}{[4][5][6][7][8][16][17][18][19]} \\
{[20][25][26][27][29]-[54]}\end{array}$ \\
\hline & $\mathrm{CT}+$ & Yes (17), NA (31) & \\
\hline \multirow[t]{3}{*}{ MRI } & $\mathrm{T} 1$ & $\begin{array}{l}\text { Hyper (6), hypo (13), iso (2), mixte (2), } \\
\text { NA ( } 25)\end{array}$ & \\
\hline & $\mathrm{T} 2$ & Hyper (6), hypo (4), mixte (11), NA (27) & [4] [5] [6] [7] [8] [16] [17] [18] [19] \\
\hline & T1+ Gado & Yes (28), No (2), NA (18) & [20] [25] [26] [27] [29]-[54] \\
\hline $\begin{array}{l}\text { Mass } \\
\text { Effect }\end{array}$ & & Yes (7), No (21), NA (20) & \\
\hline \multirow{8}{*}{$\begin{array}{l}\text { Type of } \\
\text { LC }\end{array}$} & & $3 / 4 \lambda L C ; 1 / 4 \kappa \mathrm{LC}(1)$ & [36] \\
\hline & & $\lambda L C(18)$ & $\begin{array}{l}{[7][8][18][20][26][31][32][33]} \\
{[41][45][47][50][53]}\end{array}$ \\
\hline & & $1 / 2 \lambda L C ; 1 / 2 \kappa \mathrm{LC}(1)$ & [29] \\
\hline & & $\lambda L C ; \kappa \mathrm{LC} ; \mathrm{TTR}(3)$ & [16] [19] [37] \\
\hline & & $\lambda L C ; \kappa \mathrm{LC}(3)$ & [27] [43] [54] \\
\hline & & $\lambda L C ; \operatorname{SAP}(3)$ & [8] [38] \\
\hline & & $\lambda L C$; Anti cystatin $(1)$ & [39] \\
\hline & & $\mathrm{NA}(18)$ & $\begin{array}{l}{[4][5][6][18][25][30][34][35]} \\
{[40][42][44][46][48][49][51][52]}\end{array}$ \\
\hline
\end{tabular}

$\mathrm{NA}=$ not available; $\mathrm{CT}-=$ native $\mathrm{CT} ; \mathrm{CT}+=$ post contrast $\mathrm{CT}$; hypo = hypo dense or intense; hyper = hyper dense or intense; Mixte $=$ hypo-hyper-intense; gado $=$ gadolinium; $\mathrm{LC}=$ light chain, $\lambda \mathrm{LC}=$ Lambda light chain; $\kappa \mathrm{LC}=$ Kappa light chain; TTR = transthyretrin; $\mathrm{SAP}=$; $\lambda \mathrm{LC}$-- = Lambda LC negative.

and it may show a hypo, hyper-signal or a combination of both on T2-WI. Following gadolinium infusion, whatever the signal type on T1 and T2-WI, the lesion almost enhances except in two cases [4] [7]. The type of enhancement varied from patchy [7] [38], stellate [51], to irregularly radiating enhancement [16] [18] [19] [31] [34] [35] [37] [40] [43] [44] [50] [51].

Others radiological examinations, occasionally performed, included Flurodeoxyglucose positron emission tomography (FDG-PET) scan [34] [40] [47] [54], brain scintigrapy [25] [29] [33] [49] MR spectroscopy (MRS) [40] [50] [51], arteriography [7] [17] [18] [19] [25] [26] [27] [29] [32] [39] [40] [49], and MR angiography [38].

Most patients underwent a biopsy whether by stereotactic or free hand technique; 10 had had lesion excision and in 7 cases autopsy established [5] [6] [7] [25] [42] [45] or confirmed [29] the diagnosis.

Mostly all amyloidomas were diagnosed on the basis of the dichromism and apple green birefringence characteristic of amyloid under polarized light and in only 30 cases the type of protein was specified (see Table 2). Most amyloidoma were pure $\lambda \mathrm{LC}$ type (18 cases) and in 10 patients $\lambda \mathrm{LC}$ was associated with kappa light chain $(\kappa \mathrm{LC})$, serum amyloid P protein (SAP), or transthyretrin (TTR) immunoglobulin secretion. Plasma cells were found within 17 lesions close to amor- 
phous magma or within the vascular sheath [6] [7] [16] [18] [19] [20] [25] [26] [29] [30] [36] [45] [47] [50] [53].

The management of amyloidoma is still controversial. Most patients had no other treatment than the "wait and see" attitude. Radiotherapy was performed in 5 patients [8] [38] [50] including a patient which has been irradiated before diagnosis [44] while immunotherapy [8] [18] and/or corticotherapy [7] [18] [40] were seldom used. The follow up data were incongruent although some authors reported a long term follow up over 5 years [8] [29] [36] [44]. No case showed malignant transformation but two patients experienced a brain haemorrhage [18] including a lethal one [29].

\section{Discussion}

Although more than 25 different proteins are known to self-assemble and form fibrillar amyloid structures in Humans, only about one third of amyloid proteins, known to be linked to disease, produce fibrillar deposits including amyloidoma in the CNS [1].

\subsection{Physiopathology}

The molecular mechanisms underlying brain amyloidoma formation and deposition are still unidentified, and the matter is whether the amyloid fibril protein is derived from components which leak from the vessels or the protein is synthesised at the site of deposition [29]. Additionally, even if the overall majority of brain amyloidomas are caused by the deposition of $\lambda \mathrm{LC}$ type, the relationship to specific brain tropism and damage are unknown.

It has been suggested that in systemic amyloidosis the amyloid fibril protein is typically produced at distant sites and carried in the bloodstream with deposition at multiple sites, whereas in localized amyloidosis the protein is typically deposited at the site of production and not transported in the bloodstream [55]. Several points promote the latter hypothesis for the development of amyloidoma brain restricted: 1) the very local character of the disease; 2 ) the apparently intact blood-brain barrier prevents the permeation of the circulating precursor proteins through the vessels wall; 3) local tumour-like amyloid deposits of the $\lambda \mathrm{LC}$ type, are likely to originate from a brain restricted plasma cell clone [7] [29] [39] [45] or may result from an amyloidogenic plasmocytoma of the brain [56]; 4) Recent works have demonstrated monotypic plasma cells (with cytoplasmic staining for either $\lambda \mathrm{LC}$ or $\kappa \mathrm{LC}$ ) along peri-vascular sheaths and occasionally between or adjacent to amyloid masses [6] [7] [16] [18] [19] [20] [25] [26] [29] [30] [36] [45] [47] [50] [53] [57] while in those lacking plasma cells, it has been hypothesised that they may represent a "burn out stage" of the disease [58] [59]; 5) immuno-electron microscopy study of a localized $\lambda \mathrm{LC}$ amyloidose of the stomach indicates that some amyloid fibrils may be produced within the rough endoplasmic reticulum of the plasma cells $[60]$; 6) $\lambda \mathrm{LC}$ protein type was present in the majority of the reported cases while mixed forms ( $\lambda \mathrm{LC}$ and $\kappa \mathrm{LC}$ ) were 
scarce; 7) the determination of the amino acid and genetic sequences of most amyloid precursor proteins have recently been investigated and demonstrated several genetic mutations and gene rearrangement [1] [2] [7] [56]. All this suggest that amyloidomas are related to a benign proliferation of a single clone of plasma cells [57], usually of a modest size (median 7\% of total cells [61]), with somatic mutation caused by unknown factors of the brain microenvironment. This may explain either the long-lasting time to produce the voluminous amounts of a basic ( $\lambda \mathrm{LC}$ ) amyloid masses and its benign clinical course.

\subsection{Clinical Study}

At presentation, the mean age of patients harbouring a cerebral amyloidoma is 52 years, and men are slightly younger than women and there is a slight female predominance.

The natural history of this rare lesion is not fully understood, its clinical course seems benign as demonstrated by some reports in which a long-lasting clinical history is reported [8] [27] [37] [45]. However in some cases it is not obvious whether signs and symptoms are due to the disease [41] [45], although a long lasting history is documented by several cases in which the disease was initially documented radiologically [19] [33] or proved by histology [29].

There are no specific clinical features for brain amyloidoma. The clinical presentation is similar to that of slowly growing neoplasm. Signs and symptoms vary according to the location and the severity of brain involvement. Although seizure was a frequent onset, often linked with a normal neurological examination, signs and symptoms of intracranial hypertension have rarely been mentioned [7] [53]. Many patients present cognitive dysfunction and neurological deficits including gait disturbances [8] [26] [38], motor deficits [7] [8] [17] [20] [36], dizziness [50] visual trouble [4] [25] [26] [35] [45] [49], hallucination [7], resulting from disturbance of cortex or white matter functions.

\subsection{Radiology}

Cerebral amyloidoma occurs mostly in supra-tentorial compartment (90\%), without side predominance. It may occur, either as a single (58\%) or multiple lesions (42\%), the latter involving both hemispheres in $25 \%$. Simultaneous supra and infra tentorial compartments involvement is rare; the pons being constantly involved in the latter.

On native CT scan the lesion most often appears as a homogeneous or heterogeneous hyper-density and it invariably enhances following iodine infusion. Calcification, mass effect, and oedema are lacking.

On T1-WI, amyloidoma has not specific feature it may show a hyper, iso, or hypo-intense signal. On T2-WI a mixed or patchy distribution with areas of high and low signal intensity is frequently observed. The exact reason for the different signals in the mass is unclear, but it is likely to represent an inhomogeneous amyloid deposition throughout the lesion and the areas with much denser amy- 
loid deposits would show brighter signal [44]. The exact mechanism underlying the signal hypo-intensity of amyloid on the long-TR images is complex and uncertain [62].

On gadolinium-enhanced T1-WI, irregular faint or intense enhancement of the lesion with a more or less important irradiating edge of the tumour has been observed in several cases [16] [18] [19] [31] [33] [34] [35] [36] [37] [43] [44] [50] [51]. The marked enhancement following contrast administration is felt to be secondary to the disruption of the blood brain barrier, attributed to the amyloid involvement in the blood vessel walls seen microscopically [19] [26] while the radial aspect, at the edge of the tumour, may indicate amyloid deposit along the vessels, a finding that has been observed in pathology specimens [19]. Furthermore, on reviewing the imaging or surgical findings (when available), we found that most often the lesion develops within the white matter close to the ventricle system (80\%) and thickening of the lateral ventricular wall is not rare as disclosed by radiological [17] [18] [19] [33] [37] [40] [41] [43] [44] [50] [52] and anatomical findings [6] [25] [29]. Cortical compromises are rare [20] [26] [30] even when the lesion extends to the sub-cortical area [18] [19] [31] [34] [35] [37] [43] [44] [50].

The ADC study may be normal [18], our case] while the perfusion sequences study may reveal a delayed perfusion without hyper-perfusion and even a hypoperfusion within the enhanced area [43] [50], our case]. FDG-PET scan may reveal a hypo-metabolic area [20] [41] [54] or an area of increased uptake [40] [47] whereas cerebral angiography always discloses an avascular mass.

\subsection{Diagnosis}

The diagnosis of amyloidoma, poses a particular problem. Although the radiologic exams reveal the lesion, imaging findings are not consistent with brain tumour even if the majority of presenting cases were initially diagnosed as intra-cerebral neoplasm including gliomas [16] [17] [31] [43] lymphoma [17] [39] [our case], infectious or inflammatory diseases [18] [43] and arterio-venous malformation [19].

Our review reveals that MRI characteristics of brain amyloidoma are: a paraventricular location with radials enhancement of the tumour edge following gadolinium infusion, together with lack of neo angiogenesis, mass effect, and oedema. Thus these features should support the preoperative diagnosis and histological examination is only mandatory for the diagnosis of the type of protein deposit which determines the class of amyloidoma.

\subsection{Pathology}

The amyloidoma consists of large confluent or isolated acellular masses of pale eosinophilic deposits, mostly found within the white matter and centred or not on blood vessels [25] [29] [39] [41] [44] [50] [54]. These deposits are characterized by positive histological staining with Congo red and they must demonstrate 
green birefringence when viewed under polarized light; this is a requirement for the diagnosis of the disease [63]. The specificity of Congo-red tissue staining for amyloidosis is being almost 100\% [64]. Although the amyloid deposit was invariably found in the interstitium as well as within the walls of blood vessels, it always was confined to the lesions and did not irregularly extend into surrounding parenchyma [7] [16] [27] [30] [40] as opposed to tCAA. The intervening parenchyma may demonstrate pronounced axonal swelling and degeneration with myelin loss, lipid laden macrophages and marked reactive astrocytosis [6] [42] [51] [53]. Lymphocytic infiltrates [6] [7] [16] [25] [33] [40] [45] [47] [50] [53], our case], minimal number of plasma cells, and small foci of calcification [6] [7] [19] [43] [44] [45] could be closely associated with some deposits.

Immunohistochemistry: Only 30 cases have been investigated immunohistochemically: 18 showed an isolated $\lambda \mathrm{LC}$ expression and in 10 cases $\lambda \mathrm{LC}$ expression was associated with another protein expression mostly $\kappa \mathrm{LC}$ and 2 cases were both $\lambda \mathrm{LC}$ and $\kappa \mathrm{LC}$ negative. Although bi-clonality of a monoclonal protein can exist in a patient, [39] [45], some reports have demonstrated immunohistochemically $\lambda \mathrm{LC}$ expression associated with TTR, SAP, and anti Cystatin immunoglobulin expression [8] [16] [19] [37] [38] [39] suggesting that amyloidoma is a complex protein deposit. Thus formal doubts have been raised about the reliability of immunohistochemistry in determining the amyloidoses type; immunohistochemistry is limited by the small number of antibodies available that can be simultaneously studied in a single tissue section [8] and electron microscopic study alone is not useful in differentiating various types of amyloidoses [65]. Proteomic analyses have provided a more reliable pattern of amyloidoma which are actually complex proteins deposits. Mass spectroscopy (MS) of all amyloidoma, studied by Rodriguez et al, disclosed $\lambda \mathrm{LC}$ and some lesions showed additional immunoglobulin and Apolipoprotein-derived (Apo) including SAP, ApoE, and ApoA-IV peptides [8] and according to Pascali, amyloid deposits, irrespective of their clinical type and chemical nature, also contain a non fibrillar glycoprotein, that represent up to $15 \%$ of the deposit [66]. However, the respective role and relationship of these protein complexes are unclear.

\subsection{Differential Diagnosis}

Because local amyloidosis can occur within meningiomas [67], pituitary adenomas [68], lymphoma [69], vascular malformation [70], choroid plexus papilloma and carcinoma [9], the lack of neoplasic cells is mandatory for amyloidoma diagnosis.

The brain parenchyma can be affected by other types of amyloid including LCDD [71] [72] and tCAA [73] [74] [75] which must be ruled out. LCDD differ from amyloidoma by their lack of intense red Congo stain and birefringence in polarized light microscopy [71] [72] and they show tendency to $\kappa \mathrm{LC}$ deposit although some case involving the brain showed $\lambda \mathrm{LC}$ deposit [71]. Central nervous system amyloidoma is a different entity from systemic amyloidosis or from the 
more common congophilic amyloid angiopathy [19] both histopathologically and radiologically. tCAA refers to diffuse parenchymal deposition of amyloid with a focal mass like lesion which mostly involve the wall of cortical and leptomeningeal arteries, usually sparing the white matter except in the sub-cortical zones [73] [74] [75], in contrast amyloidoma is a focal deposition of amyloid mostly found within the white matter. In addition, on post-contrast imaging, amyloidoma invariably shows post-contrast enhancement, whereas tCAA usually does not [73] [74] [75].

After histological verification, the second step must be to exclude the presence of systemic amyloidoses and plasma cell dyscrasia. Thus biological, radiological and haematological screening and bone or fat biopsy are mandatory for evaluation of systemic diseases.

\subsection{Management}

Currently, no firm level A, evidence-based data exist for managing brain amyloidoma. The management of brain amyloidomas varied including surgical excision, radiotherapy [8] [38] [44] [50], corticotherapy [7] [8] [18] [40], our case], immunosuppressive therapy [8] [18], our case] and single observation, which was the most applied attitude.

The ideal treatment is to inhibit aggregation or to render existing deposits soluble; such passive immunotherapy directed against the amyloid deposits has been explored in AL amyloidoses with promising results: when one such prototypic antibody was injected into an amyloidoma-bearing mouse, the antibody localized only in the tumour and led to the elimination of tumours [76] but to our knowledge, at this time, no such agents for Human in vivo use exist.

From the neurosurgical point of view, a risk-adapted strategy involves suppression of the "tumour" whenever possible with no functional risks. Total or sub-total removal rarely seems necessary and feasible, owing to the most frequent deep seated para-ventricular location of amyloidoma. Such removal was initially performed mostly due to concerns of primary brain tumour, so most cases have been diagnosed by means of stereotactic or open biopsy. Therefore surgical resection could be performed for cortical locations and whenever feasible with no detrimental risks and stereotactic biopsy is a minimal kind of surgery to perform the diagnosis of the type of protein folding. Schroder et al suggested that for such biopsied cases, one can wait and control the local findings, especially when no malignant plasma cells are present in the biopsy specimen [39]. This point of view is supported by the fact that there is no proof of efficacy of others medical treatments such as corticosteroids and immunosuppressive therapy with high dose methotrexate [our case], thalidomide [18] or melphalan [8] [18] furthermore, such systemic treatment could have detrimental effects for localized amyloidoses with a unique organ dysfunction [77].

Because some amyloidomas have recurred after surgical resection [29] and biopsied lesions have shown growth with [36] [38] [53] or without clinical wors- 
ening [17] [20] [41] [47] brain radiation therapy is another way to be considered as in some cases it provided disease control [8] [38] [44] [50].

\subsection{Follow up}

From the limited reported follow-up data, the clinical course seems benign. Localized amyloidomas seem to have no documented risk for increased mortality. Unlike CAA, in which the risk of intracranial haemorrhage is known to be high [73] [74] [75], the risk of haemorrhage in brain amyloidoma is undetermined; brain haemorrhage has occurred in two patients [18] [29] and microscopic foci of haemorrhage have been described in another case [16]. There has been no observed malignant transformation or other pathology related to amyloidoma although scarcely the development of systemic disease several years after initial diagnosis of amyloidoma has been reported [55] [66]. Survival of patients with amyloidoma brain restricted varied from 10 months to 15 years.

\subsection{Limits of the Study}

A major limitation of this study is that, despite extensive research, only case reports were found that could be considered eligible for consideration. No level A, evidence-based, medical studies exist to support an official recommendation or guidelines for managing brain amyloidoma.

\section{Conclusion}

The most important MRI clues of amyloidoma brain restricted are the non-tumour like pattern of a cerebral mass developing near the ventricle with a fine, irregular, radiating margin enhancement with lack of oedema, and mass effect on surrounding anatomy. These important radiological features could possibly add specificity to this disease and should consistently raise diagnosis suspicion of brain amyloidoma.

\section{Acknowledgements}

For help with editing in English, and other valuable advice, we thank Dr Mabandine Djagri Temoukale.

\section{Conflicts of Interest}

The authors declare no conflicts of interest regarding the publication of this paper.

\section{References}

[1] Rostagno, A., Holton, J.L., lashley, T., Revesz, T. and Ghiso, J. (2010) Cerebral Amyloidosis: Amyloid Subunits, Mutants and Phenotypes. Cellular and Molecular Life Sciences, 67, 581-600. https://doi.org/10.1007/s00018-009-0182-4

[2] Walker, L.C. and LeVine, H. (2000) The Cerebral Proteopathies: Neurodegenerative Disorders of Protein Conformation and Assembly. Molecular Neurobiology, 21, 83-95. https://doi.org/10.1385/MN:21:1-2:083 
[3] Matsumoto, T., Tani, E., Maeda, Y. and Natsume, S. (1985) Amyloidomas in the Cerebellopontine Angle and Jugular Foramen. Journal of Neurosurgery, 62, 592-596. https://doi.org/10.3171/jns.1985.62.4.0592

[4] Samandouras, G., Teddy, P.J., Cadoux-Hudson, T. and Ansorge, O. (2006) Amyloid in Neurosurgical and Neurological Practice. Journal of Clinical Neuroscience, 13, 159-167. https://doi.org/10.1016/j.jocn.2005.05.009

[5] Saltykow, S. (1935) Zur Frage des lokalen Amyloids der Hirngefasse. Bemerkung zu dem Aufsatz von Morgenstern. Virchows Archiv (Pathol Anat), 295, 590. https://doi.org/10.1007/BF01889298

[6] Lampert, P. (1958) Tumor Forming Atypical Amyloidosis of the Choroid Plexus with Invasion of the Cerebral White Matter. Journal of Neuropathology \& Experimental Neurology, 17, 604-611. https://doi.org/10.1097/00005072-195810000-00007

[7] Laeng, R.H., Altermatt, H.J., Scheithauer, B.W. and Zimmermann, D.R. (1998) Amyloidomas of the Nervous System. A Monoclonal B-Cell Disorder with Monotypic Amyloid Light Chain 1 Amyloid Production. Cancer, 82, 362-374.

https://doi.org/10.1002/(SICI)1097-0142(19980115)82:2<375::AID-CNCR18>3.0.C O;2-W

[8] Rodriguez, F.J., Gamez, J.D., Vrana, J.A., Theis, J.D., Giannini, C., Scheithauer, B.W., Parisi, J.E., Lucchinetti, C.F., Pendlebury, W.W., Bergen, H.R. 3rd and Dogan, A. (2008) Immunoglobulin Derived Depositions in the Nervous System: Novel Mass Spectrometry Application for Protein Characterization in Formalin-Fixed Tissues. Laboratory Investigation, 88, 1024-1037. https://doi.org/10.1038/labinvest.2008.72

[9] Suck, M.L.T., Lara, C.S., Bojórquez, D.R., Vega, R. and López, M.C. (2008) Depósito de amiloide en tumores de plexos coroides. Estudio patológico. Archives of Neuroscience (Mex), 13, 112-117.

[10] Barr, R. and Lampert, P. (1979) Intrasellar Amyloid Tumor. Acta Neuropathologica (Berl), 21, 157-159.

[11] DeCastro, S., Sparks, J.T., Lapey, J.D. and Freidberg, S.R. (1976) Amyloidoma of the Gasserian Ganglion. Surgical Neurology, 6, 357-359.

[12] Simoens, W.A., Van den Hauwe, L., Van Hedent, E., Warson, F., Demaeseneer, R., Williams, D. and De Schepper, A.M.A. (2000) Amyloidoma of the Skull Base. American Journal of Neuroradiology, 21, 1559-1562.

[13] McAnena, O.J., Feely, M.P. and Kealy, W.F. (1982) Spinal Cord Compression by Amyloid Tissue. Journal of Neurology, Neurosurgery and Psychiatry, 45, 10671069. https://doi.org/10.1136/jnnp.45.11.1067

[14] Pawar, S., Kay, C.J., Anderson, H.H. and Breitfeld, V. (1982) Primary Amyloidoma of the Spine. Journal of Computer Assisted Tomography, 6, 1175-1177. https://doi.org/10.1097/00004728-198212000-00021

[15] Pizov, G. and Soffer, D. (1986) Amyloid Tumor (Amyloidoma) of a Peripheral Nerve. Archives of Pathology \& Laboratory Medicine, 110, 969-970.

[16] Gandhi, D., Wee, R. and Goyal, M. (2003) CT and MR Imaging of Intracerebral Amyloidoma: Case Report and Review of the Literature. American Journal of Neuroradiology, 24, 519-522.

[17] Caerts, B., Mol, V., Sainte, T., Wilms, G., Van den Bergh, V. and Stessens, L. (1997) CT and MRI of Amyloidoma of the CNS. European Radiology, 7, 474-476. https://doi.org/10.1007/s003300050186

[18] Labro, H., Al-Kadhimi, Z., Djmil, M., Oghlakian, R. and Alshekhlee, A. (2009) Brain Amyloidoma with Cerebral Hemorrhage. The Journal of the American Os- 
teopathic Association, 109, 372-375.

[19] Symko, S.C., Hattab, E.M., Steinberg, G.K. and Lane, B. (2001) Imaging of Cerebral and Brain Stem Amyloidomas. American Journal of Neuroradiology, 22, 1353-1356.

[20] Fischer, B., Palkovic, S., Rickert, C., Weckesser, M. and Wassmann, H. (2007) Cerebral AL Lambda-Amyloidoma: Clinical and Pathomorphological Characteristics. Review of the Literature and of a Patient. Amyloid, 14, 11-19. https://doi.org/10.1080/13506120600960585

[21] Sirohi, B. and Powles, R. (2006) Epidemiology and Outcomes Research for MGUS, Myeloma and Amyloidoses. European Journal of Cancer, 42, 1671-1683. https://doi.org/10.1016/j.ejca.2006.01.065

[22] Tomiyasu, U. and Rosen, V.J. (1970) Amyloid Masses Involving Brain. VI. Congres International de Neuropathologie, Paris. Masson, Paris, 1144-1145.

[23] Parmar, H., Rath, T., Castillo, M. and Gandhi, D. (2010) Imaging of Focal Amyloid Depositions in the Head, Neck, and Spine: Amyloidoma. American Journal of Neuroradiology, 31, 1165-1170. https://doi.org/10.3174/ajnr.A1977

[24] Jahrig, A., Spaar, F.W., Lindermeyer, J., Schrôder, R. and Linke, R.P. (2011) A Historical Cerebral Amyloidoma (SPA) Classified Retrospectively as AL $\lambda$-Type. A Case Report. Amyloid, 18, 114-116. https://doi.org/10.3109/13506129.2011.574354042

[25] Townsend, J.J., Tomiyasu, U., MacKay, A. and Wilson, C.B. (1982) Central Nervous System Amyloid Presenting as a Mass Lesion Report of Two Cases. JNS, 56, 439-442. https://doi.org/10.3171/jns.1982.56.3.0439

[26] Spaar, F.W., Goebel, H.H., Volles, E. and Wickboldt, J. (1981) Tumor-Like Amyloid Formation (Amyloidoma) in the Brain. Journal of Neurology, 224, 171-182. https://doi.org/10.1007/BF00313279

[27] Harris, J.M. (1979) Primary Cerebral Amyloidoma. Journal of Neuropathology \& Experimental Neurology, 38, 318. https://doi.org/10.1097/00005072-197905000-00062

[28] Hawkins, C., Gray, B., Moulton, R. and Bilbao, J.M. (2002) Cerebral Amyloidoma. Canadian Association of Neuropathologists Abstracts of Papers and Cases Presented at the 42nd Annual Meeting. Canadian Journal of Neurological Sciences, 29, 394-401. https://doi.org/10.1017/S0317167100002298

[29] Eriksson, L., Sletten, K., Benson, L. and Westermark, P. (1993) Tumour-Like Localized Amyloid of the Brain Is Derived from Immunoglobulin Light Chain. Scandinavian Journal of Immunology, 37, 623-626. https://doi.org/10.1111/j.1365-3083.1993.tb01673.x

[30] Gallucci, M., Caulo, M., Splendiani, A., Russo, R., Ricci, A. and Galzio, R. (2002) Neuroradiological Findings in Two Cases of Isolated Amyloidoma of the Central Nervous System. Neuroradiology, 44, 333-337. https://doi.org/10.1007/s00234-001-0728-0

[31] Lôhr, M., Monoranu, C.M., Vince, G.H. and Ernestus, R.I. (2010) Primary Brain Amyloidoma Mimicking High-Grade Glioma. Joint Meeting mit der Brasilianischen Gesellschaft für Neurochirurgie am 20.

[32] Renard, D., Campello, C., Rigau, V., de Champfleur, N. and Labauge, P. (2008) Primary Brain Amyloidoma: Long-Term Follow-Up. Archives of Neurology, 65, 979-980. https://doi.org/10.1001/archneur.65.7.979

[33] Smadja, P., Viaud, B., Durand, L., Bauchet, L., Bossot, P., Hane, B., Campello, C. and Bonafé, A. (2000) Amyloidoma of the Central Nervous System: CT and MR 
Aspects. Journal of Radiology, 81, 975-978. (In French)

[34] Van Roy, J. and De Bie, J. (2009) Frontal Syndrome Resulting from an Intracerebral Amyloidoma. Tijdschrift voor Psychiatrie, 51, 847-852. (In Dutch)

[35] McMillion, L., Melton, D.M. and Erickson, J.C. (2008) Teaching Neuroimage: Primary Cerebral Amyloidoma Mimicking CNS Neoplasm. Neurology, 71, e68. https://doi.org/10.1212/01.wnl.0000335933.82019.16

[36] Blattler, T., Siegel, A.M., Jochum, W., Aguzzi, A. and Hess, K. (2001) Primary Cerebral Amyloidoma. Neurology, 56, 777. https://doi.org/10.1212/WNL.56.6.777

[37] Foreid, H., Barroso, C., Evangelista, T., Campos, A. and Pimentel, J. (2010) Intracerebral Amyloidoma: Case Report and Review of the Literature. Clinical Neuropathology, 29, 217-222. https://doi.org/10.5414/NPP29217

[38] Hochberg, F.H., Rodriguez, F.J., Atkinson, J.L.D., Shaw, E.G., Keegan, B.M. and Kantarci, O.H. (2009) A 54-Year-Old Woman with Progressive Gait Disturbance and MRI Abnormalities. Neurology, 73, 466-474.

https://doi.org/10.1212/WNL.0b013e3181b1644d

[39] Schröder, R., Linke, R.P., Voges, J., Heindel, W. and Sturm, V. (1995) Intracerebral A Lambda Amyloidoma Diagnosed by Stereotactic Biopsy. Clinical Neuropathology, 14, 347-350.

[40] Sin, A.H., Gonzalez-Toledo, E., Fowler, M., Minagar, A. and Nanda, A. (2008) Amyloidoma Presenting as a Butterfly Glioma on Positron Emission Tomography Scan and Magnetic Resonance-Spectroscopy: A Case Report and Review of the Literature. Journal of the Louisiana State Medical Society, 160, 44-47, 49-50.

[41] Tabatabai, G., Baehring, J. and Hochberg, F.H. (2005) Primary Amyloidoma of the Brain Parenchyma. Archives of Neurology, 62, 477-480.

https://doi.org/10.1001/archneur.62.3.477

[42] Hori, A., Kitamoto, T., Tateishi, J., Hann, P. and Friede, R.L. (1988) Focal Intracerebral Accumulation of a Novel Type of Amyloid Protein. An Early Stage of Cerebral Amyloidoma? Acta Neuropathologica, 76, 212-215. https://doi.org/10.1007/BF00688106

[43] Landau, D., Avgeropoulos, N. and Ma, J. (2010) Cerebral Amyloidoma Mimicking Intracranial Tumor: A Case Report. Journal of Medical Case Reports, 4, 308. https://doi.org/10.1186/1752-1947-4-308

[44] Lee, J., Krol, G. and Rosenblum, M. (1995) Primary Amyloidoma of the Brain: CT and MR Presentation. American Journal of Neuroradiology, 16, 712-714.

[45] Linke, R.P., Gerhard, L. and Lottspeich, F. (1992) Brain-Restricted Amyloidoma of Immunoglobulin Lambda-Light Chain Origin Clinically Resembling Multiple Sclerosis. Biological Chemistry Hoppe-Seyler, 373, 1201-1209. https://doi.org/10.1515/bchm3.1992.373.2.1201

[46] Da Rocha, A.J., Da Silva, C.J., Leopoldino, J.F.S. and De Andrade, V.P. (2011) Intra Cerebral Amyloidoma Imaging Findings Might Support Preoperative Diagnosis. Arquivos de Neuro-Psiquiatria, 69, 413. https://doi.org/10.1590/S0004-282X2011000300033

[47] Meir, K., Maly, B., Shoshan, Y., Maly, A. and Soffer, D. (2005) Cerebral Amyloidoma Diagnosed Intraoperatively with Squash Preparations: A Case Report. Acta Cytologica, 49, 195-198. https://doi.org/10.1159/000326133

[48] Moller, M., Freund, M., Greiner, C., Schwindt, W., Gaus, C. and Heindel, W. (2005) Real Time fMRI: A Tool for the Routine Presurgical Localisation of the Motor Cortex. European Radiology, 15, 292-295. https://doi.org/10.1007/s00330-004-2513-Z 
[49] Moreno, A.J., Brown, J.M., Brown, T.J., Graham, G.D. and Yedinak, M.A. (1983) Scintigraphic Findings in a Primary Cerebral Amyloidoma. Clinical Nuclear Medicine, 8, 528-530. https://doi.org/10.1097/00003072-198311000-00003

[50] Nossek, E., Bashat, D.B., Artzi, M., Rosenberg, K., Lichter, I., Shtern, O., Ami, H.B., Aizenstein, O., Vlodavsky, E., Constantinescu, M. and Ram, Z. (2009) The Role of Advanced MR Methods in the Diagnosis of Cerebral Amyloidoma. Amyloid, 16, 94-98. https://doi.org/10.1080/13506120902879939

[51] Ragel, B.T., Blumenthal, D.T., Browd, S.R., Salzman, K.L. and Jensen, R.L. (2006) Intracerebral Amyloidoma Can Mimic High-Grade Glioma on Magnetic Resonance Imaging and Spectroscopy. Archives of Neurology, 63, 906-907. https://doi.org/10.1001/archneur.63.6.906

[52] Vanhoenacker, F., Van Paesschen, R., Hauman, R., van den Hauwe, L. and Parizel, P.M. (2001) Cerebral Amyloidoma. JBR-BTR, 84, 79.

[53] Cohen, M., Lanska, D., Roessmann, U., Karaman, B., Ganz, E., Whitehouse, P. and Gambetti, P. (1992) Amyloidoma of the CNS. I. Clinical and Pathologic Study. Neurology, 42, 2019-2023. https://doi.org/10.1212/WNL.42.10.2019

[54] Tallo, A., Weyns, F., Peuskens, D., Engelborghs, K., Wuyts, J., IJsewijn, T., Vandevenne, J. and Gelin, G. (2007) Intracerebral Primary Amyloidoma: CT and MR Imaging. Abstracts/Surgical Neurology, 68, 192-204. https://doi.org/10.1016/j.surneu.2007.06.050

[55] Buadi, F. (2010) Localized Amyloidosis in Amyloidosis: Diagnosis and Treatment. In: Gertz, M.A. and Rajkumar, S.V., Eds., Contemporary Hematology, Humana Press, Springer Science \& Business Media, Berlin, Chap. 7, 95-106. https://doi.org/10.1007/978-1-60761-631-3 7

[56] Gambetti, P. and Russo, C. (1998) Humain Brain Amyloidoses. Nephrology Dialysis Transplantation, 13, 33-40. https://doi.org/10.1093/ndt/13.suppl 7.33

[57] Vidal, R.G., Ghiso, J., Gallo, G., Cohen, M., Gambetti, P.L. and Frangione, B. (1992) Amyloidoma of the CNS. II. Immunohistochemical and Biochemical Study. Neurology, 42, 2024-2028. https://doi.org/10.1212/WNL.42.10.2024

[58] Krumholz, A., Weiss, H.D., Jiji, V.H., Bakal, D. and Kirh, M.B. (1982) Solitary Intracranial Plasmocytoma/Two Patients with Extended Follow Up. Annals of Neurology, 11, 529-532. https://doi.org/10.1002/ana.410110514

[59] Lucas, D.R., Knox, F. and Davies, S. (1982) Apparent Monoclonal Origin of Lymphocytes and Plasma Cells Infiltrating Ocular Adnexal Amyloid Deposit: Report of 2 Cases. British Journal of Ophthalmology, 66, 600-606. https://doi.org/10.1136/bjo.66.9.600

[60] Ishihara, T., Takahashi, M., Koga, M., Yotoka, T., Yamashita, Y. and Uchino, F. (1991) Amyloid Fibril Formation in the Rough Endoplasmic Reticulum of Plasma Cell from a Patient with Localized A $\lambda$ Amyloidosis. Laboratory Investigation, 64, 265-271.

[61] Perfetti, V., Palladini, G. and Merlini, G. (2004) Immune Mechanisms of AL Amyloidoses. Drug Discovery Today: Disease Mechanisms, 1, 365-373.

http://www.drugdiscoverytoday.com https://doi.org/10.1016/j.ddmec.2004.11.008

[62] Gean-Marton, A.D., Kirsch, C.F., Vezina, L.G. and Weber, A.L. (1991) Focal Amyloidoses of the Head and Neck: Evaluation with CT and MR Imaging. Radiology, 181, 521-525. https://doi.org/10.1148/radiology.181.2.1924798

[63] Steensma, D.P. (2001) "Congo" Red: Out of Africa? Archives of Pathology \& Laboratory Medicine, 125, 250-252. 
[64] Gertz, M.A., Li, C.Y., Shirahama, T. and Kyle, R.A. (1988) Utility of Subcutaneous Fat Aspiration for the Diagnosis of Systemic Amyloidosis. Internal Medicine, 148, 929-933. https://doi.org/10.1001/archinte.1988.00380040169024

[65] Gillmore, J.D., Lovat, L.B. and Hawkins, P.N. (1999) Amyloidosis and the Liver. Journal of Hepatology, 30, 17-33.

[66] Pascali, E. (1995) Diagnosis and Treatment of Primary Amyloidoses. Critical Reviews in Oncologyl Hematology, 19, 149-181. https://doi.org/10.1016/1040-8428(94)00135-G

[67] Foschini, M.P., Dadda, T., Bordi, C. and Eusebi, V. (1993) Amyloid Stroma in Meningiomas. Virchows Archiv, 422, 53-59. https://doi.org/10.1007/BF01605133

[68] Rôcken, C., Uhlig, H., Saeger, W., Linke, R.P. and Fehr, S. (1995) Amyloid Deposits in Pituitaries and Pituitary Adenomas: Immunohistochemistry and in Situ Hybridization. Endocrine Pathology, 6, 135-143. https://doi.org/10.1007/BF02739876

[69] Ellie, E., Vergier, B., Duche, B., Rivel, J., Vital, C. and Loiseau, P. (1990) Local Amyloid Deposits in a Primary Central Nervous System Lymphoma. Study of a Stereotactic Brain Biopsy. Clinical Neuropathology, 9, 231-233.

[70] Peterson, E.W. and Schulz, D.M. (1961) Amyloid in Vessels of a Vascular Malformation in Brain. Archives of Pathology, 72, 480-483.

[71] Popovic, M., Tavcar, R., Glavac, D., Volavsek, M., Pirtosek, Z. and Vizjak, A. (2007) Light Chain Deposition Disease Restricted to the Brain: The First Case Report. Human Pathology, 38, 179-184. https://doi.org/10.1016/j.humpath.2006.07.010

[72] Vital, A., Ellie, E. and Loiseau, H. (2010) A 61-Year-Old Man with Instability of Gait and Right Hand Clumsiness. Brain Pathology, 20, 273-274.

https://doi.org/10.1111/j.1750-3639.2009.00349.x

[73] Awasthi, D., Voorhies, R.M., Eick, J. and Mitchell, W.T. (1991) Cerebral Amyloid Angiopathy Presenting as Multiple Intracranial Lesions on Magnetic Resonance Imaging: Case Report. Journal of Neurosurgery, 75, 458-460. https://doi.org/10.3171/jns.1991.75.3.0458

[74] Briceno, C.E., Resch, L. and Bernstein, M. (1987) Cerebral Amyloid Angiopathy Presenting as a Mass Lesion. Stroke, 18, 234-239.

https://doi.org/10.1161/01.STR.18.1.234

[75] De Andrade, G.C., Silveira, R.L., Pinheiro, N., Melo Rocha, E.M.M. and Pittella, J.E.H. (2006) Angiopatia Amiloide Cerebral Simulando Tumor Cerebral. Arquivos de Neuro-Psiquiatria, 64, 153-156. https://doi.org/10.1590/S0004-282X2006000100034

[76] Hrncic, R., Wall, J., Wolfenbarger, D.A., Murphy, C.L., Schell, M., Weiss, D.T. and Solomon, A. (2000) Antibody-Mediated Resolution of Light Chain-Associated Amyloid Deposits. The American Journal of Pathology, 157, 1239-1246. https://doi.org/10.1016/S0002-9440(10)64639-1

[77] Comenzo, R.L. (2007) Current and Emerging Views and Treatments of Systemic Immunoglobulin Light Chain (AL) Amyloidoses [Review]. Contributions to $\mathrm{Ne}$ phrology, 153, 195-210. https://doi.org/10.1159/000096768 